\title{
Blocking the PI3K pathway or the presence of high concentrations of EGF inhibits the spontaneous activation of ovine primordial follicles in vitro
}

\section{Luciana da Paz dos Santos ${ }^{1}$, Jamile Maiara da Silva Santos ${ }^{1}$, Vanúzia Gonçalves Menezes ${ }^{1}$, Ricássio de Sousa Barberino $^{1}$, Bruna Bortoloni Gouveia ${ }^{1}$, Agnes Yasmin Pitombeira Cavalcante ${ }^{1}$, Thae Lanne Barbosa Gama Lins $^{1}$, Rodrigo José de Sousa Gonçalves ${ }^{1}$, Juliana Jales de Hollanda Celestino², Maria Helena Tavares de Matos ${ }^{1,3}$}

\author{
${ }^{1}$ Nucleus of Biotechnology Applied to Ovarian Follicle Development, Federal University of São Francisco Valley, \\ Petrolina, PE, Brazil. \\ ${ }^{2}$ Institute of Health Sciences, University of International Integration Lusophone African-Brazilian, Acarape, CE, Brazil.
}

\begin{abstract}
The aims of this study were to verify the effects of Epidermal Growth Factor (EGF) on the morphology, primordial follicle activation, growth and proliferation of granulosa cells of ovine follicles cultured in situ, as well as the effect of a PI3K inhibitor on the follicular activation. Ten ovine ovaries were divided into fragments, being one fixed for histological analysis (fresh control). The remaining fragments were cultured for 7 days in control medium $\left(\alpha-\mathrm{MEM}^{+}\right)$alone or supplemented with EGF (1, 10, 50, 100 or $200 \mathrm{ng} / \mathrm{mL})$. Follicles were classified as normal or atretic, as primordial or growing, and the oocyte and follicle diameters were measured. PCNA immunohistochemistry was performed in the fresh control and in treatment that showed the best results for follicular activation. Pharmacologic inhibition of PI3K activity was performed through pretreatment in media added with $50 \mu \mathrm{M}$ LY294002 for $1 \mathrm{~h}$. The percentage of normal follicles decreased $(\mathrm{P}<0.05)$ after 7 days of culture in all treatments compared to the fresh control. A significant reduction in the percentage of primordial follicles and an increase $(\mathrm{P}<0.05)$ in the growing ones were observed in all treatments compared to fresh control. Furthermore, both the control medium and $1 \mathrm{ng} / \mathrm{mL}$ EGF promoted an increase $(\mathrm{P}<0.05)$ in follicular activation compared to other EGF treatments. The PCNA-positive cells in the EGF treatment were higher $(\mathrm{P}<0.05)$ than in fresh control and $\alpha-\mathrm{MEM}^{+}$. Pretreatment of ovarian tissue with PI3K inhibitor significantly inhibited $(\mathrm{P}<0.05) \alpha-$ $\mathrm{MEM}^{+}$-stimulated primordial follicle activation, but had no effect on EGF-stimulated activation $(\mathrm{P}>0.05)$. In conclusion, $\mathrm{PI} 3 \mathrm{~K}$ pathway mediates the in vitro spontaneous activation of sheep primordial follicles. Moreover, EGF may act indirectly on follicular activation by promoting granulosa cell proliferation at $1 \mathrm{ng} / \mathrm{mL}$, and EGF inhibited follicle activation in concentrations similar or higher than $10 \mathrm{ng} / \mathrm{mL}$.
\end{abstract}

Keywords: culture, folliculogenesis, preantral follicle, sheep.

\section{Introduction}

The majority of follicles within ovarian cortical tissue are quiescent primordial follicles, so the first consideration of an in vitro growth system should be to optimize initiation of primordial follicles growth and to support early follicle development (Telfer and Zelinski, 2013). Some paracrine or endocrine factors that might regulate these early steps of folliculogenesis have been identified (Monget et al., 2012), including the locally produced epidermal growth factor (EGF; Silva et al., 2016).

The biological functions of the EGF are mediated by the EGF receptor (EGFR), which was localized in the oocyte and granulosa cells of all follicle development stage (hamster: Roy and Greenwald, 1990; human: Maruo et al., 1993; swine: Singh et al., 1995; caprine: Gall et al., 2004). In vitro studies have shown that EGF reduced atresia levels in isolated swine preantral follicles (Mao et al., 2004), maintained prepubertal cat primordial follicle viability (Fujihara et al., 2014), promoted primordial follicle activation (caprine: Celestino et al., 2009; rat: Li-Ping et al, 2010), follicular growth (bovine: Wandji et al., 1996a; caprine: Silva et al., 2013), proliferation of the granulosa cells from swine primary and secondary follicles (Morbeck et al., 1993), and stimulated the antrum formation (bovine: Gutierrez et al., 2000; caprine: Celestino et al., 2011; Silva et al., 2013; ovine: Santos et al., 2014). Moreover, the association of EGF (in a fixed concentration: 100 $\mathrm{ng} / \mathrm{mL}$ ) with either Indole Acetic Acid (IAA) or Follicle Stimulating Hormone (FSH) maintained normal follicle morphology after ovine ovarian tissue culture (Andrade et al., 2005). In latter study, however, the authors did not analyze an optimum curve for the relationship between EGF and early follicular growth. Therefore, a dose response study to determine which is the optimum dose of EGF that might maintain the normal morphology and stimulate the in vitro activation of ovine primordial follicles is necessary.

Furthermore, although the EGFR is among the tyrosine kinase receptors that can activate the phosphatidylinositol 3-kinase (PI3K) pathway (Liu et al., 2006), the intracellular signaling pathways activated during ovine primordial follicle activation remain largely uncharacterized and are fundamental to understand the molecular systems responsible for this fundamental aspect of ovarian development and function that influences fertility (John et al., 2008). Some studies have demonstrated that pharmacological manipulation of the PI3K pathway, using PI3K inhibitors such as LY294002 (Granville et al., 2006), could potentially give a better understanding of the function and regulatory mechanisms of this pathway on 
follicular activation (Keating et al., 2009; Sobinoff et al., 2012; Zhao et al., 2014). However, it remains to be seen whether PI3K or its inhibitor LY294002 can be used to maintain morphologically normal follicles and to promote follicle activation in sheep ovaries cultured in vitro.

Therefore, the aim of this study was to analyze whether a dose-response curve of EGF might have beneficial effects on the morphology, primordial follicle activation, growth and proliferation of granulosa cells of ovine follicles using in situ organ culture. In addition, LY294002 was used to further verify the hypothesis that pharmacological inhibition of the activation of the PI3K pathway would inhibit follicle growth in vitro, especially under exogenous EGF stimuli.

\section{Material and methods}

\section{Source of ovarian tissue}

Ovarian cortical tissues ( $\mathrm{n}=10$ ovaries) were collected at a local abattoir from five adult (1-3 years old) mixed-breed sheep. Immediately post-mortem, pairs of ovaries were washed once in $70 \%$ alcohol (Dinâmica, São Paulo, Brazil) and then twice in minimum essential medium buffered with HEPES (MEM-HEPES) and supplemented with antibiotics (100 $\mu \mathrm{g} / \mathrm{mL}$ penicillin and $100 \mu \mathrm{g} / \mathrm{mL}$ streptomycin). The ovaries were transported within $1 \mathrm{~h}$ to the laboratory in tubes containing MEM-HEPES and antibiotics at $4^{\circ} \mathrm{C}$ (Chaves et al., 2008). Unless noted otherwise, supplements, EGF and chemicals used in this study were purchased from Sigma Aldrich Chemical Co. (St. Louis, MO, USA).

\section{In vitro culture of preantral follicles}

In the laboratory, the ovarian cortex was cut into approximately $3 \mathrm{~mm}$ x $3 \mathrm{~mm}$ ( $1 \mathrm{~mm}$ thick) small pieces under sterile conditions using a scalpel blade. For each animal, one slice of tissue was randomly selected and immediately fixed for histological analysis (fresh control). Thereafter, the remaining tissue fragments of each ovarian pair were randomly divided into six experimental groups. The fragments of ovarian cortex were cultured individually in $1 \mathrm{~mL}$ of culture medium in 24-well culture dishes for 7 days; the culture conditions were $39^{\circ} \mathrm{C}$ in an atmosphere of $5 \% \mathrm{CO}_{2}$ in the air. The base culture medium (control) consisted of $\alpha$-MEM (MEM $\alpha$, nucleosides, catalog number 12571, Gibco, Invitrogen, Karlsruhe, Germany, $\mathrm{pH}$ 7.2-7.4) supplemented with ITS $(10 \mu \mathrm{g} / \mathrm{mL}$ insulin, $5.5 \mu \mathrm{g} / \mathrm{mL}$ transferrin and $5.0 \mathrm{ng} / \mathrm{mL}$ sodium selenite), $2 \mathrm{mM}$ glutamine, $2 \mathrm{mM}$ hypoxanthine, $1.25 \mathrm{mg} / \mathrm{mL}$ bovine serum albumin (BSA) and $50 \mu \mathrm{g} / \mathrm{mL}$ ascorbic acid and then referred as $\alpha-\mathrm{MEM}^{+}$. For the experimental conditions, the control medium was supplemented with EGF (recombinant Epidermal Growth Factor human E9644) at different concentrations $(1,10,50,100$ or $200 \mathrm{ng} / \mathrm{mL}$ ). Each treatment was repeated five times, thus using the ovaries of five different animals. The culture medium was replenished every other day.
Morphological analysis and assessment of in vitro follicular growth

Tissues from all treatments (fresh control, control medium and EGF treatments) were fixed in 4\% buffered paraformaldehyde (Dinâmica) for $18 \mathrm{~h}$ and then dehydrated in increasing concentrations of ethanol. After paraffin embedding (Dinâmica), the ovine tissues were cut into $5 \mu \mathrm{m}$ sections, and every section was mounted on glass slides and stained by periodic acid Schiff (Dinâmica) and hematoxylin (Vetec, São Paulo, Brazil). Follicle stage and survival were assessed microscopically on serial sections. Coded anonymized slides were examined by microscopy (Nikon, Tokyo, Japan) at 400X magnification.

The developmental stages of preantral follicles have been defined previously (Silva et al., 2004): primordial (one layer of flattened granulosa cells around the oocyte) or growing follicles (intermediate: one layer of flattened to cuboidal granulosa cells; primary: one layer of cuboidal granulosa cells, and secondary: two or more layers of cuboidal granulosa cells around the oocyte and no sign of antrum formation). Additionally, these follicles were classified individually as histologically normal when an intact oocyte was present and surrounded by granulosa cells that were well organized in one or more layers and have no pyknotic nuclei. Atretic follicles were defined as those with a retracted oocyte, pyknotic nucleus and/or disorganized granulosa cells detached from the basement membrane. Overall, 150 follicles were evaluated for each treatment (30 follicles per treatment for one repetition $\mathrm{x}$ five replicates $=150$ follicles), totaling 1050 preantral follicles.

To evaluate follicular activation (transition from primordial to growing follicles, evidenced by the presence of granulosa cells with cuboidal morphology and proliferation) and growth, only morphologically normal follicles with a visible oocyte nucleus were recorded, and the proportion of primordial and growing follicles was calculated at day 0 (fresh control) and after 7 days of culture. In addition, from the basement membrane, major and minor axes of each oocyte and follicle were measured using Image-Pro Plus ${ }^{\circledR}$ software (Media Cybernetics Inc., Silver Spring, MD, USA). The average of these two measurements was used to determine the diameters of both the oocyte and the follicle.

Proliferating cell nuclear antigen (PCNA) immunohistochemistry

Proliferating cells were detected with proliferating cell nuclear antigen (PCNA) immunohistochemistry in the fresh control and in treatments that showed the best results for follicular activation in vitro. For PCNA analysis, additional pairs of sheep ovaries ( $n=6$ ovaries) were collected, transported to the laboratory, fragmented and cultured (in $\alpha-\mathrm{MEM}^{+}$or in $\alpha-\mathrm{MEM}^{+}$containing $1 \mathrm{ng} / \mathrm{mL}$ EGF) as described above. Immunohistochemistry was performed as described in previous studies (Silva et al., 2004; 
Hoffman et al., 2008) with some modifications. Briefly, $5 \mu \mathrm{m}$ sections were cut on a microtome (EasyPath, São Paulo, Brazil) and mounted in Starfrost glass slides (Knittel, Braunschweig, Germany). The slides were incubated in citrate buffer (Dinâmica) at $95^{\circ} \mathrm{C}$ in a deckloaking chamber for $40 \mathrm{~min}$ to retrieve antigenicity, and endogenous peroxidase activity was prevented by incubation with $3 \% \quad \mathrm{H}_{2} \mathrm{O}_{2}$ (Dinâmica) and methyl ethanol (QEEL, São Paulo, Brazil) for $10 \mathrm{~min}$. Nonspecific binding sites were blocked using 1\% normal mouse serum (Biocare, Concord, USA) diluted in phosphate-buffered saline (PBS). Subsequently, the sections were incubated in a humidified chamber for 90 $\mathrm{min}$ at room temperature with rabbit polyclonal antiPCNA (1:500; Santa Cruz Biotechnology, Santa Cruz, CA, USA). Then, the sections were incubated for $30 \mathrm{~min}$ with MACH4 Universal HRP-polymer (Biocare). The protein localization was demonstrated with diaminobenzidine (DAB; Biocare), and the sections were counterstained with haematoxylin (Vetec) for $40 \mathrm{~s}$. Negative control (reaction control) underwent all steps except the primary antibody incubation.

Only follicles that contained an oocyte nucleus were analyzed for proliferating cell assay. The number of PCNA positive cells (brown staining) was counted in ten randomly fields per treatment using Image-Pro Plus ${ }^{\circledR}$ software. The percentage of PCNA positive cells was calculated as the number of cells in proliferation out of the total number of cells (x 100).

\section{Pharmacologic inhibition of PI3K pathway}

The aim was to test the hypothesis that pharmacological inhibition of the PI3K pathway would inhibit primordial follicle activation and survival (morphology) in vitro. For this in vitro culture, additional pairs of sheep ovaries $(n=10$ ovaries) were collected, transported to the laboratory and fragmented as described above. The ovarian fragments were cultured for 7 days in the control medium $\left(\alpha-\mathrm{MEM}^{+}\right)$or in $\alpha-\mathrm{MEM}^{+}$added by $1 \mathrm{ng} / \mathrm{mL}$ EGF without the PI3K inhibitor, or in these treatments in the presence of the PI3K inhibitor $\left(\alpha-\mathrm{MEM}^{+}+\mathrm{PI} 3 \mathrm{~K}\right.$ inhibitor or EGF $1+$
PI3K inhibitor). For PI3K inhibition, $50 \mu \mathrm{M}$ of the PI3K specific inhibitor LY294002 (Cell Signaling Technologies, Danvers, USA) was added to the control medium $\left(\alpha-\mathrm{MEM}^{+}\right)$for $1 \mathrm{~h}$ (before EGF supplementation) at $39^{\circ} \mathrm{C}$ and $5 \% \mathrm{CO}_{2}$ in the air. Media were changed and treatments replenished every other day (including the inhibitor). The concentration of LY294002 $(50 \mu \mathrm{M})$ was chosen according to Ryan et al. (2008) and Adhikari et al. (2013).

\section{Statistical analysis}

Data from morphologically normal, primordial and growing follicles from both cultures (without and with the PI3K inhibitor) were submitted to the ShapiroWilk test to verify normal distribution of residues and homogeneity of variances. Therefore, ANOVA and the Tukey's test were applied for comparison among treatments. The values of proliferating cells were submitted to Chi-square test. The results of follicular survival and growth were expressed as the mean $\pm \mathrm{SD}$, and the results of follicular activation were expressed as the mean \pm SEM. Differences were considered to be statistically significant when $\mathrm{P}<0.05$.

\section{Results}

\section{Follicular morphology and development after in vitro culture}

The preantral follicles from the control tissue showed centrally located oocytes and granulosa cells surrounded by normal intact basement membranes (Fig. 1A), similarly to the morphology of the follicles cultured in medium containing $1 \mathrm{ng} / \mathrm{mL}$ EGF (Fig. 1B). After 7 days of culture with higher concentrations of EGF $(100$ or $200 \mathrm{ng} / \mathrm{mL})$, atretic follicles with a retracted oocyte and disorganized granulosa cells could be observed (Fig. 1C). The percentage of morphologically normal follicles decreased significantly after 7 days of culture in all treatments compared to the fresh control (Fig. 2). However, no significant difference was observed among the treatments.
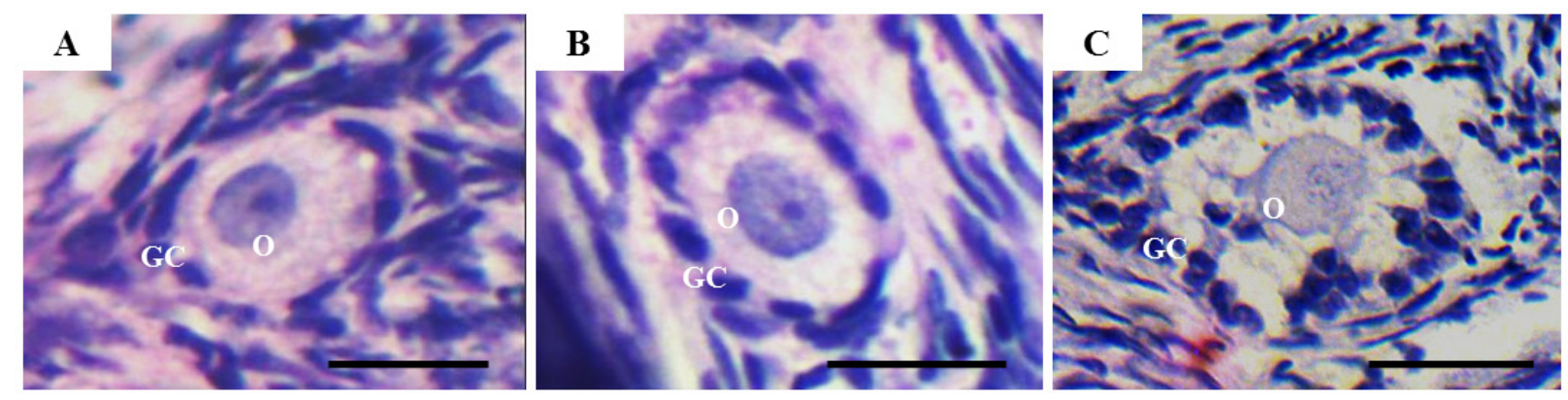

Figure 1. Normal follicles (A) in the fresh control, (B) cultured in medium containing $1 \mathrm{ng} / \mathrm{mL}$ EGF and (C) atretic follicle in medium containing $200 \mathrm{ng} / \mathrm{mL}$ EGF. O: Oocyte; GC: Granulosa cells. Scale bars: $30 \mu \mathrm{m}$. 


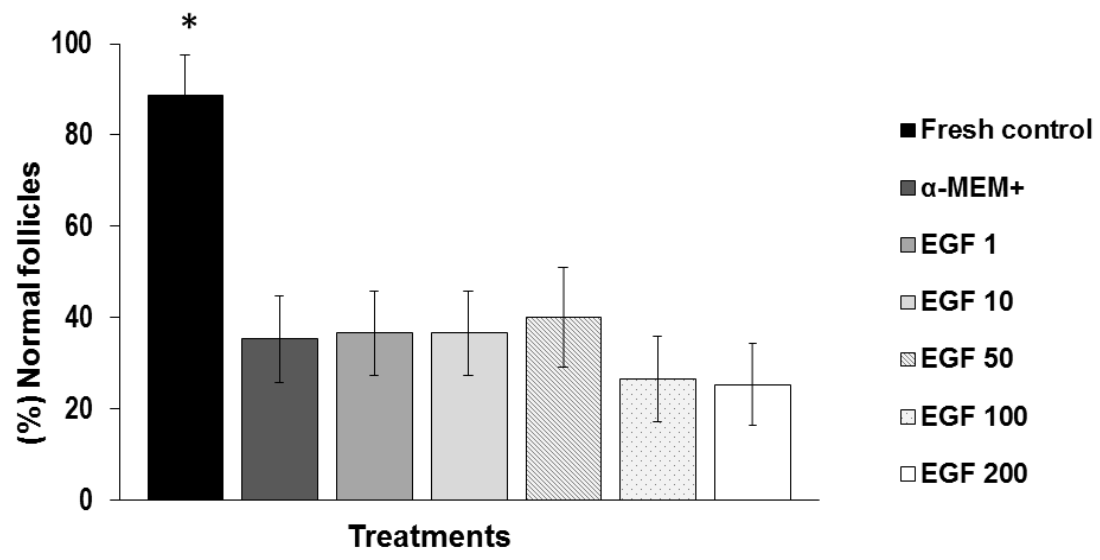

Figure 2. Percentages (mean $\pm \mathrm{SD}$ ) of morphologically normal follicles in the fresh control and after 7 days of in vitro culture in different concentrations of EGF. * Differs significantly from fresh control $(\mathrm{P}<0.05)$.

In all culture conditions, a significant reduction in the percentage of primordial follicles, reflecting an increase in the percentage of growing ones, was observed in all treatments compared to the fresh control group (Fig. 3A and B). Furthermore, both the control medium $\left(\alpha-\mathrm{MEM}^{+}\right)$and the medium containing $1 \mathrm{ng} / \mathrm{mL}$ EGF promoted a significant increase in primordial follicle activation compared to the other EGF treatments. A significant reduction in the percentage of activation was found after in vitro culture when the concentration of EGF was increased from 1 to 10 and $200 \mathrm{ng} / \mathrm{mL}$. According to Table 1, no significant influence of EGF on the follicle or oocyte diameters was observed.
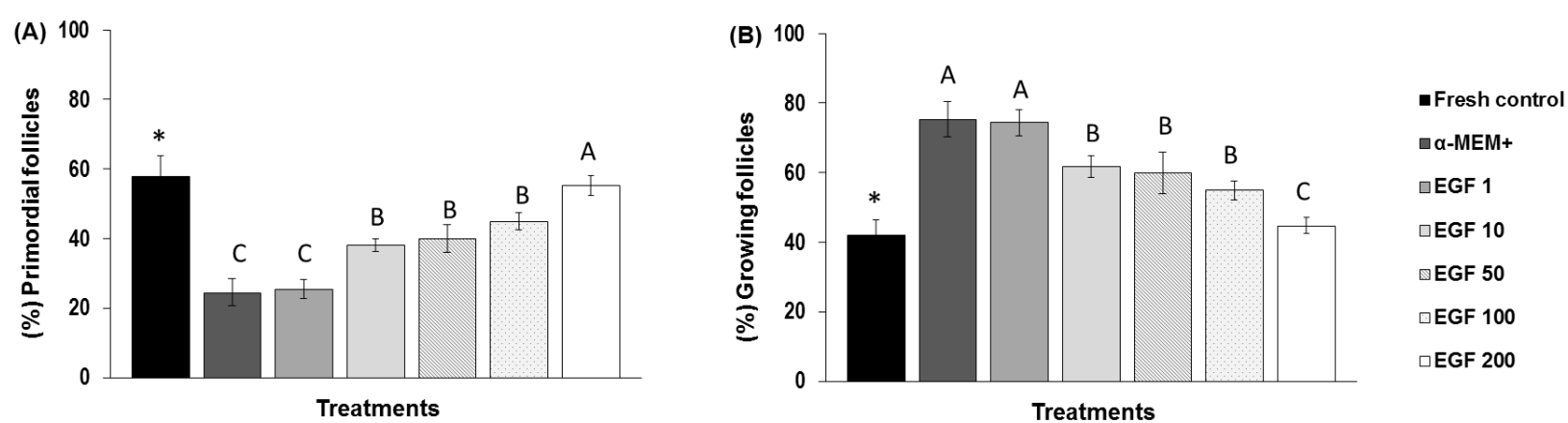

Figure 3. Percentages (mean \pm SEM) of normal primordial (A) and growing (B) follicles in the fresh control and after 7 days of in vitro culture in different concentrations of EGF. ${ }^{*}$ Differs significantly from fresh control $(\mathrm{P}<0.05)$. $(\mathrm{A}, \mathrm{B}, \mathrm{C})$ Different letters denote significant differences among treatments $(\mathrm{P}<0.05)$.

Table 1. Mean oocyte and follicular diameter (mean $\pm \mathrm{SD}$ ) in the fresh control and after in vitro culture of ovine preantral follicle in the control medium or different concentrations of EGF.

\begin{tabular}{lcc}
\hline Treatments & Follicular diameter $(\mu \mathrm{m})$ & Oocyte diameter $(\mu \mathrm{m})$ \\
\hline Fresh control & $53.41 \pm 8.80$ & $43.05 \pm 6.39$ \\
\hline$\alpha$-MEM & $55.64 \pm 19.28$ & $39.25 \pm 11.34$ \\
EGF 1 & $48.71 \pm 10.02$ & $32.81 \pm 8.08$ \\
EGF 10 & $51.15 \pm 11.07$ & $35.15 \pm 7.52$ \\
EGF 50 & $46.45 \pm 5.70$ & $33.43 \pm 4.77$ \\
EGF 100 & $49.24 \pm 14.38$ & $32.72 \pm 7.58$ \\
EGF 200 & $51.55 \pm 8.89$ & $38.24 \pm 7.10$ \\
\hline
\end{tabular}

Evaluation of granulosa cell proliferation using PCNA immunohistochemistry

Proliferating cells were analyzed in the fresh control and in the media that promoted higher follicular activation (control medium and medium containing $1 \mathrm{ng} / \mathrm{mL}$ EGF). Ovarian follicles cultured in $\alpha-\mathrm{MEM}^{+}$did not show or showed less proliferating cells (Fig. 4A). Nevertheless, positive PCNA staining in the granulosa cells was commonly found in ovarian tissue that had been cultured in medium containing $1 \mathrm{ng} / \mathrm{mL}$ EGF (Fig. 4B). Negative control did not show staining for PCNA (Fig. 4C). The percentage of PCNA-positive cells in the EGF treatment $(55.0 \%)$ was significantly higher than in the fresh control $(13.0 \%)$ and $\alpha-\mathrm{MEM}^{+}$ groups (5.0\%; Fig. 5).

\section{Pharmacologic inhibition of PI3K pathway}

Pretreatment of ovarian tissue with PI3K 
inhibitor did not influence the percentage of normal follicles ( $\mathrm{P}>0.05$; Fig. 6). Interestingly, the pretreatment of ovarian tissue with LY294002 significantly inhibited the activation of primordial follicles observed in $\alpha$ $\mathrm{MEM}^{+}$, but had no significant effect on EGF-stimulated activation (Fig. 7A and B).
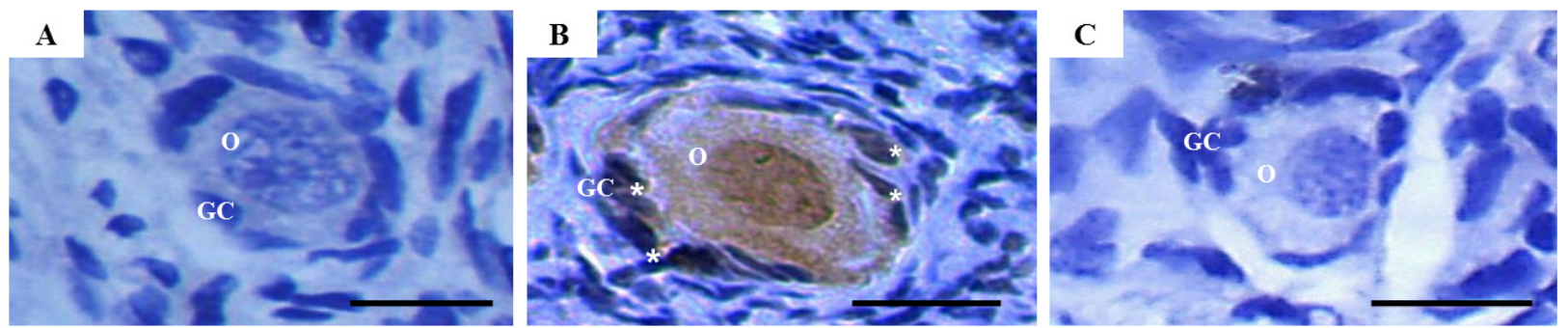

Figure 4. Immunohistochemical detection of PCNA in $\alpha-\mathrm{MEM}^{+}(\mathrm{A})$, in medium containing $1 \mathrm{ng} / \mathrm{mL}$ EGF (B) and negative control (C). O: Oocyte; GC: Granulosa cells. Asterisc: PCNA-positive cell. Scale bars: $30 \mu \mathrm{m}$.

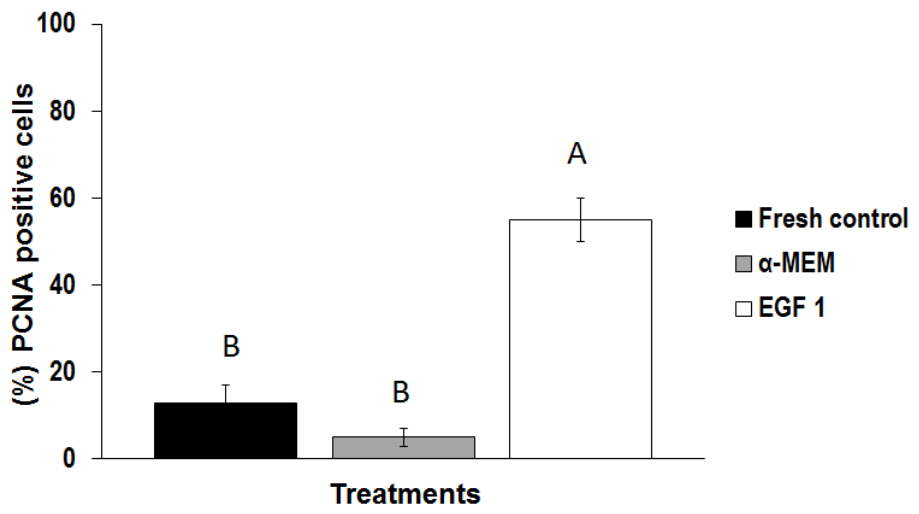

Figure 5. Percentages of PCNA positive cells in the fresh control, control medium $\left(\alpha-\mathrm{MEM}^{+}\right)$and medium containing $1 \mathrm{ng} / \mathrm{mL}$ EGF. $\left({ }^{\mathrm{A}, \mathrm{B}}\right)$ Different letters denote significant differences among treatments $(\mathrm{P}<0.05)$.

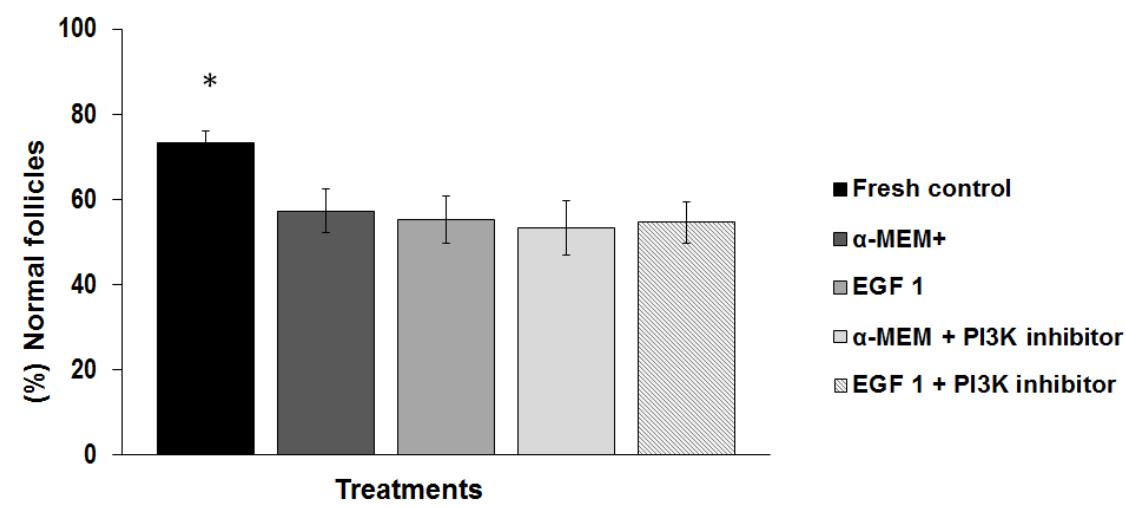

Figure 6. Percentages (mean $\pm \mathrm{SD}$ ) of morphologically normal follicles in the fresh control, after in vitro culture in $\alpha-\mathrm{MEM}^{+}$or $1 \mathrm{ng} / \mathrm{mL}$ EGF, and after pharmacologic inhibition of PI3K activity. *Differs significantly from fresh control $(\mathrm{P}<0.05)$.
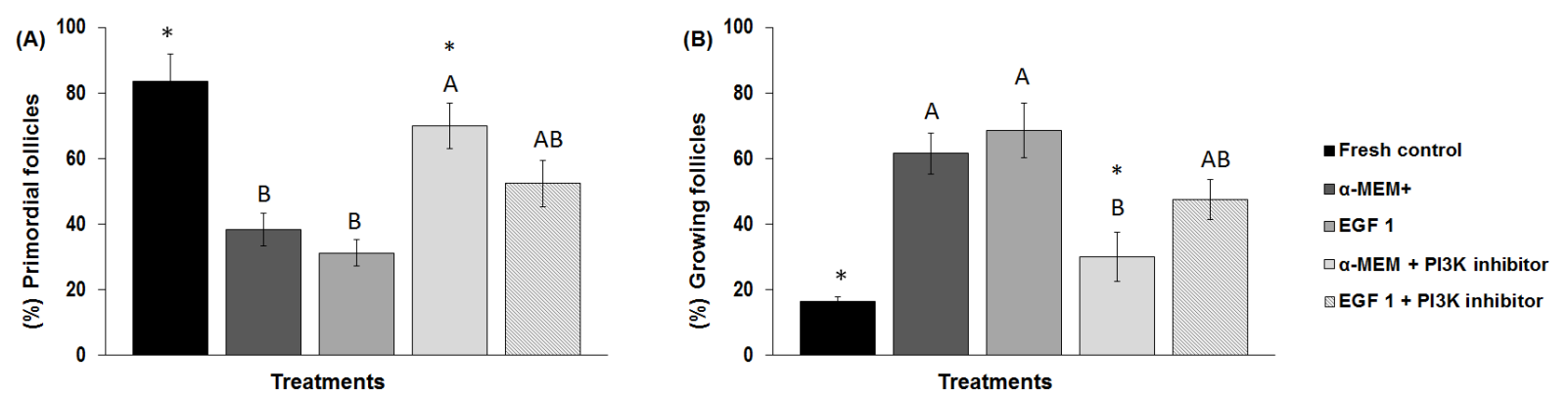

Figure 7. Percentages (mean \pm SEM) of normal primordial (A) and growing (B) follicles in the fresh control, after in vitro culture in $\alpha-\mathrm{MEM}^{+}$or $1 \mathrm{ng} / \mathrm{mL}$ EGF, and after pharmacologic inhibition of PI3K activity. ${ }^{*}$ Differs significantly from fresh control $(\mathrm{P}<0.05)$. $\left({ }^{\mathrm{A}, \mathrm{B}, \mathrm{C}}\right)$ Different letters denote significant differences among treatments $(\mathrm{P}<0.05)$. 


\section{Discussion}

To the best of our knowledge, this is the first study to report the PI3K signaling pathway regulating the spontaneous primordial follicle activation in sheep ovary, and to use a PI3K specific inhibitor (LY294002) to further verify the action of PI3K pathway on follicular morphology and activation with response to exogenous EGF stimuli. Addition of EGF to the culture medium had no effect on follicle survival (morphologically normal follicles) compared to the control medium. Similar results were reported after 7 days of culture of goat and sheep ovarian fragments in medium containing $10 \mathrm{ng} / \mathrm{mL}$ EGF (Andrade et al., 2014). However, EGF at 1 or $10 \mathrm{ng} / \mathrm{mL}$ maintained follicular morphology and ultrastructure after culture of goat ovarian tissue (Celestino et al., 2009). This divergence in results might be related to the differences between the species and the media. Celestino et al. (2009) used MEM Eagle (catalog number M0268, Sigma Aldrich Chemical Co), which has a simplest composition than $\alpha$-MEM containing additional amino acids and vitamins. Therefore, the effect of EGF was more evident using the simplest MEM. Other study showed that only the association of either FSH or IAA with EGF $(100 \mathrm{ng} / \mathrm{mL})$ was efficient for maintaining ovine follicular survival after 6 days of culture (Andrade et al., 2005).

In the current study, both the control medium $\left(\alpha-\mathrm{MEM}^{+}\right)$and the medium containing $1 \mathrm{ng} / \mathrm{mL}$ EGF increased primordial follicle activation compared to the fresh control and other EGF treatments. When cortical pieces were placed in culture, primordial follicles would be released from the influence of inhibitor(s) of medullary origin (Cushman et al., 2002), or the stimulatory factor(s) would override the effect of inhibitor(s) (Braw-Tal, 2002), allowing follicle activation to be initiated spontaneously even in the control medium (Wandji et al., 1996b; Braw-Tal and Yossefi, 1997). Other possible explanation for the spontaneous activation is that the fragmentation step, i.e. cutting ovaries into cubes increases actin polymerization and disrupts Hippo signaling pathway, leading to an increase in the expression of connective tissue growth factor and related factors that promote primordial follicle growth in vitro (Hsueh et al., 2015).

Although previous studies reported that EGF is involved in goat (at 1, 10, and $50 \mathrm{ng} / \mathrm{mL}$; Celestino et al., 2009) and rat (at $50 \mathrm{ng} / \mathrm{mL}$ : Li-Ping et al., 2010) primordial follicle development, we observed no further improvement on follicle activation when the tissues were cultured in $1 \mathrm{ng} / \mathrm{mL}$ EGF (similar to that in $\alpha-\mathrm{MEM}^{+}$). It is possible that under these conditions, factors other than EGF are probably involved in the initiation of primordial follicle growth in sheep, such as Kit ligand (Cavalcante et al., 2016). In this respect, other studies have demonstrated that EGF is not essential for the activation of bovine (at $10 \mathrm{ng} / \mathrm{mL}$; Braw-Tal and Yossefi, 1997; Derrar et al., 2000), caprine (at 100 $\mathrm{ng} / \mathrm{mL}$; Silva et al., 2004) or feline (at 50, 100 or 200 $\mathrm{ng} / \mathrm{mL}$; Fujihara et al., 2014) primordial follicles. Moreover, in this study, it was noteworthy that the increase in EGF concentration $(10,50,100$, and specially the highest concentration of $200 \mathrm{ng} / \mathrm{mL}$ ) inhibited spontaneous follicle activation compared to the control medium. There is evidence of an opposing effect of EGF action depending on species and the dose provided. For example, EGF acts as a survival factor in the neonatal kidney cells of the rat, but potentiates apoptosis under the same conditions in the neonatal mice (Kiley et al., 2005). Moreover, in a transfected hamster cell line expressing EGFR, a low EGF concentration promotes proliferation, whereas a high dose induces cell-cycle arrest and apoptosis (Zhao et al., 2006).

Nevertheless, an additive effect on granulosa cell proliferation was observed when ovarian fragments were cultured in $1 \mathrm{ng} / \mathrm{mL}$ EGF compared to the fresh control and the control medium. The most probable explanation of the lowest PCNA expression in the granulosa cells of the fresh control might be that the ovary contains mainly primordial follicles (Shea et al., 2014), in which occasionally PCNA-positive cells have been found (Silva et al., 2004). Hemamalini et al. (2003) have shown that EGF $(50 \mathrm{ng} / \mathrm{mL})$ is a mitogenic factor promoting ovine granulosa cell proliferation and improvement of DNA synthesis. It is well established that granulosa cells secrete growth factors, such as Kit ligand (Silva et al., 2006), that can regulate primordial follicle activation (Cavalcante et al., 2016). Thus, EGF likely is exerting its impact indirectly on ovine primordial follicle activation by stimulating the proliferation of granulosa cells and further secretion of other stimulatory factor.

It is possible that key tyrosine kinase receptors respond to their ligands in oocytes by direct binding and activation of the PI3K pathway to promote the initiation of primordial follicle growth (Li et al., 2010). Therefore, to verify the involvement of the PI3K in the regulation of ovine primordial follicle activation in vitro, we tested the hypothesis that pharmacological inhibition of the PI3K pathway with LY294002 would inhibit the initiation of follicle growth. LY294002 has been used at different concentrations (from $1 \mu \mathrm{M}$ to $50 \mu \mathrm{M}$ ) and incubation periods (from $20 \mathrm{~min}$ to 14 days) to inhibit the PI3K pathway in different ovarian cells (Reddy et al., 2009; Mani et al., 2010; Adhikari et al., 2013; Zhang et al., 2014; Fujihara et al., 2014; Lan et al., 2017). In this study, although the concentration of the inhibitor (50 $\mu \mathrm{M}$ LY294002) is higher than most of the other studies (Keating et al., 2009; Sobinoff et al., 2012; Zhang et al., 2014; Zhao et al., 2017), our findings support the idea that this concentration was not toxic because it did not reduce the percentage of normal follicles compared to the treatment without the inhibitor. Moreover, the PI3K pathway inhibition decreased the spontaneously ovine primordial follicle activation observed after culture in the control medium, which is in agreement with previous results (rat: Keating et al., 2009; mouse: Sobinoff et al., 2012; Zhao et al., 2014). However, surprisingly, our results also provide evidence that EGF is nonessential in engaging the PI3K pathway to regulate the activation. Insulin, one component of our control medium $\left(\alpha-\mathrm{MEM}^{+}\right)$, exerts its 
biological effects primarily by activating the PI3K pathway. A previous study has shown that PI3K inhibitors inhibited insulin-stimulated Ras/Raf/Mitogenactivated protein kinase/extracellular signal-regulated kinase 1 and $2($ ERK1/2) signaling pathway, but had no significant effect on EGF-stimulated ERK1/2 phosphorylation (Liu et al., 2006). Therefore, in this study, a more reasonable explanation is that insulin present in the control medium may be involved in the primordial follicle activation through the PI3K pathway. Nevertheless, EGF may promote the initiation of follicle growth through other signaling pathways, such as mitogen-activated protein kinase (MAPK) and protein kinase C pathways (Li-Ping et al., 2010). Once more, another possibility is that EGF might be acting indirectly through the proliferation of granulosa cells to promote primordial follicle development. Our findings raise the possibility that pharmacologic agents acting upon the PI3K pathway, several of which are in clinical trials (Granville et al., 2006), may be useful in controlling follicle activation, treating infertility, or prevent the menopause in woman (John et al., 2008).

In summary, our findings advance our understanding of ovarian biology by providing the first direct evidence that the PI3K pathway mediates the in vitro spontaneous activation of primordial follicles in sheep. Moreover, this study demonstrated that EGF may act indirectly on primordial follicle development by promoting granulosa cell proliferation at a concentration of $1 \mathrm{ng} / \mathrm{mL}$, and that EGF also inhibited follicle activation in concentrations similar or higher than 10 $\mathrm{ng} / \mathrm{mL}$. The study of pathways regulating primordial follicle maintenance is necessary to clarify the biological basis of several forms of female infertility characterized by accelerated primordial follicle depletion, such as primary ovarian insufficiency.

\section{Acknowledgments}

This work was supported by FACEPE (Process APQ-0705-5.05/10). L. P. Santos is a recipient of a grant from FACEPE (Brazil). M.H.T. Matos and J.J.H. Celestino are supported by a grant from CNPq.

\section{References}

Adhikari D, Risal S, Liu K, Shen Y. 2013. Pharmacological inhibition of mTORC1 prevents overactivation of the primordial follicle pool in response to elevated PI3K signaling. PLoS One, 8(1):53810.

Andrade ER, Seneda M, Alfieri AA, Oliveira JA, Bracarense APFRL, Figueiredo JR, Toniolli R. 2005. Interactions of indole acetic acid with EGF and FSH in the culture of ovine preantral follicles. Theriogenology, 64:1104-1113.

Andrade PM, Chaves RN, Alves AMCV, Rocha RMP, Lima LF, Carvalho AA, Rodrigues APR, Campello CC, Gastal EL, Figueiredo JR. 2014. Effects of $\alpha$-MEM and TCM-199 culture media and epidermal growth factor on survival and growth of goat and sheep preantral follicles cultured in vitro. Anim Reprod, 11:567-572.
Braw-Tal R, Yossefi S. 1997. Studies in vivo and in vitro on the initiation of follicle growth in the bovine ovary. J Reprod Fertil, 109:165-171.

Braw-Tal R. 2002. The initiation of follicle growth: the oocyte or the somatic cells?. Mol Cell Endocrinol, 187:11-18.

Cavalcante AYP, Gouveia BB, Barberino RS, Lins TLBG, Santos LP, Gonçalves RJS, Celestino JJH, Matos M.H.T. 2016. Kit ligand promotes the transition from primordial to primary follicles after in vitro culture of ovine ovarian tissue. Zygote, 24:578-582.

Celestino JJH, Bruno JB, Lima-Verde IB, Matos MHT, Saraiva MV, Chaves RN, Martins FS, Lima LF, Name KPO, Campello CC, Silva JRV, Báo SN, Figueiredo JR. 2009. Recombinant epidermal growth factor maintains follicular ultrastructure and promotes the transition to primary follicles in caprine ovarian tissue cultured in vitro. Reprod Sci, 16:239-246.

Celestino JJH, Bruno JB, Saraiva MVA, Rocha RMP, Brito IR, Duarte ABG, AraújoVR, Silva CMG, Matos MHT, Campello CC, Silva JRV, Figueiredo JR. 2011. Steady-state level of epidermal growth factor (EGF) mRNA and effect of EGF on in vitro culture of caprine preantral follicles. Cell Tissue Res, 344:539-50.

Chaves RN, Martins DFS, Saraiva MVA, Celestino JJH, Lopes CAP, Correia JC, Lima-Verde IB, Matos MHT, Báo SN, Name KPO, Campello CC, Silva JRV, Figueiredo JR. 2008. Chilling ovarian fragments during transportation improves viability and growth of goat preantral follicles cultured in vitro. Reprod Fertil, 20:640-647.

Cushman RA, Wahl CM, Fortune JE. 2002. Bovine ovarian cortical pieces grafted to chick embryonic membranes: a model for studies on the activation of primordial follicles. Hum Reprod, 17:48-54.

Derrar N, Price CA, Sirard M-A. 2000. Effects of growth factors and co-culture with ovarian medulla on the activation of primordial in explants of bovine ovarian cortex. Theriogenology, 54:587-598.

Fujihara M, Comizzoli P, Keefer CL, Wildt DE, Songsasen N. 2014. Epidermal Growth Factor (EGF) Sustains In Vitro Primordial Follicle Viability by Enhancing Stromal Cell Proliferation via MAPK and PI3K Pathways in the Prepubertal, but Not Adult, Cat Ovary. Biol Reprod, 90:1-10

Gall L, Chene N, Dahirel M, Ruffini S, Boulesteix C. 2004. Expression of epidermal growth factor receptor in the goat cumulus-oocyte complex. Mol Reprod Dev, 67: 439-445.

Granville CA, Memmott RM, Gills JJ, Dennis PA. 2006. Handicapping the Race to Develop Inhibitors of the Phosphoinositide 3-Kinase/Akt/Mammalian Target of Rapamycin Pathway. Clin Cancer Res, 12:679-689.

Gutierrez CG, Ralph JH, Telfer EE, Wilmut I, Webb R. 2000. Growth and antrum formation of bovine preantral follicles in long-term culture in vitro. Biol Reprod, 62:1322-1328.

Hemamalini NC, Rao BS, Tamilmani G, D. Amarnath, R. Vagdevi, K.S. Naidu, K.K. Reddy, V.H. Rao. 2003. Influence of transforming growth factor-a, insulin-like growth factor-II, epidermal growth 
factor or follicle stimulating hormone on in vitro development of preantral follicles in sheep. Small Rumin Res, 50:11-22.

Hoffman GE, Wei LE, Luciane VS. 2008. The Importance of Titrating Antibodies for Immunocytochemical. Curr Protoc Neurosci, 45:2-12.

Hsueh AJW, Kawamura K, Cheng Y, Fauser BCJM. 2015. Intraovarian control of early folliculogenesis. Endocr Rev, 36:1-24.

John GB, Gallardo TD, Shirley LJ, Castrillon DH 2008. Foxo3 is a PI3K-dependent molecular switch controlling the initiation of oocyte growth. Dev Biol, 321:197-204.

Keating AF, Mark CJ, Sen N, Sipes G, Hoyer PB. 2009. Effect of phosphatidylinositol-3 kinase inhibition on ovotoxicity caused by 4-vinylcyclohexene diepoxide and 7, 12-dimethylbenz[a] anthracene in neonatal rat ovaries. Toxicol Appl Pharmacol, 241:127-134.

Kiley SC, Thornhill BA, Belyea BC, Neale K, Forbes MS, Luetteke NC, Lee DC, Chevalier RL. 2005. Epidermal growth factor potentiates renal cell death in hydronephrotic neonatal mice, but cell survival in rats. Kidney Int, 68:504-514.

Lan ZJ, Krause MS, Redding SD, Li X, Wu GZ, Zhou HX, Bohler HC, Ko C, Cooney AJ, Zhou J, Lei ZM. 2017. Selective deletion of Pten in theca-interstitial cells leads to androgen excess and ovarian dysfunction in mice. Mol Cell Endocrinol, 444:26-37.

Li J, Kawamurab K, Cheng Y, Liu S, Klein C, Liu S, Duanc E-K, Hsueh AJW. 2010. Activation of dormant ovarian follicles to generate mature eggs. Proc Natl Acad Sci U S A, 10:10280-10284.

Li-Ping Z, Da-Lei Z, Jian H, Liang-Quan X, Ai-Xia X, Xiao-Yu D, Dan-Feng T, Yue-Hui Z. 2010. Protooncogene c-erbB2 initiates rat primordial follicle growth via PKC and MAPK pathways. Reprod Biol Endocrinol, 8:66.

Liu L, Xie Y, Lou L. 2006. PI3K is required for insulin-stimulated but not EGF-stimulated ERK1/2 Activation. Eur J Cell Biol, 85:367-374.

Mani AM, Fenwick MA, Cheng Z, Sharma MK, Singh D, Wathes DC. 2010. IGF1 induces upregulation of steroidogenic and apoptotic regulatory genes via activation of phosphatidylinositol dependent kinase/AKT in bovine granulosa cells. Reproduction, 139:139-151.

Mao J, Smith MF, Rucker EB, Wu GM, McCauley TC, Cantley TC, Prather RS, Didion BA, Day BN 2004. Effect of epidermal growth factor and insulin-like growth factor I on porcine preantral follicular growth, antrum formation, and stimulation of granulosal cell proliferation and suppression of apoptosis in vitro. $J$ Anim Sci, 82:1967-1975.

Maruo T, Ladines-Llave CA, Samoto T, Matsuo H, Manalo AS, Ito H, Mochizuki M. 1993. Expression of epidermal growth factor and its receptor in the human ovary during follicular growth and regression. Endocrinology, 132:924-931.

Monget P, Bobe J, Gougeon A, Fabre S, Monniaux D, Dalbies-Tran. R. 2012. The ovarian reserve in mammals: A functional and evolutionary perspective. Mol Cell Endocrinol, 356:2-12.
Morbeck DE, Flowers WL, Britt JH. 1993. Response of porcine granulosa cells isolated from primary and secondary follicles to FSH, 8-bromo-cAMP and EGF in vitro. J Reprod Fertil, 99:577-584.

Reddy P, Adhikari D, Zheng W, Liang S, Hämäläinen T, Tohonen V, Ogawa $W$, Noda $T$, Volarevic S, Huhtaniemi I, Liu K. 2009. PDK1 signaling in oocytes controls reproductive aging and lifespan by manipulating the survival of primordial follicles. Human Mol Genetics, 18:2813-2824

Roy SK, Greenwald GS. 1990. Immunohistochemical localisation of epidermal growth factor-like activity in the hamster ovary with a polyclonal antibody. Endocrinology, 126:1309-1317.

Ryan EK, Glister C, Lonergan P, Martin F, Knight PG, Evans ACO. 2008. Functional significance of the signal transduction pathways Akt and Erk in ovarian follicles: in vitro and in vivo studies in cattle and sheep. J Ovarian Res, 1:1-13

Santos LP, Barros VRP, Cavalcante AYP, Menezes VG, Macedo TJS, Santos JMS, Araújo VR, Queiroz MAA, Matos MHT. 2014. Protein localization of epidermal growth factor in sheep ovaries and improvement of follicle survival and antrum formation in vitro. Reprod Dom Anim, 49:783-789.

Shea LD, Woodruff TK, Shikanov A. 2014. Bioengineering the ovarian follicle microenvironment. Annu Rev Biomed Eng, 16:29-52.

Silva J.R.V., Van Den Hurk R., Matos M.H.T., Santos R.R., Pessoa C., Moraes M.O., Figueiredo J.R. 2004. Influences of FSH and EGF on primordial follicles during in vitro culture of caprine ovarian cortical tissue. Theriogenology, 61:1691-1704.

Silva JRV, van den Hurk R, van Tol HTA, Roelen BAJ, Figueiredo JR. 2006. The Kit ligand/c-Kit receptor system in goat ovaries: Gene expression and protein localization. Zygote, 14:317-328.

Silva CMG, Castro SV, Faustino LR, Rodrigues GQ, Brito IR, Rossetto R, Saraiva MVA, Campello CC, Lobo CH, Souza CEA, Moura AAA, Donato MAA, Peixoto CA, Figueiredo JR. 2013. The effects of epidermal growth factor (EGF) on the in vitro development of isolated goat secondary follicles and the relative mRNA expression of EGF, EGF-R, FSH-R and P450 aromatase in cultured follicles. Res Vet Sci, 94:453-461.

Silva JRV, Van den Hurk R, Figueiredo JR. 2016. Ovarian follicle development in vitro and oocyte competence: advances and challenges for farm animals. Dom Anim Endocrinol, 55:123-135.

Singh B, Rutledge JM, Armstrong DT. 1995. Epidermal growth factor and its receptor gene expression and peptide localization in porcine ovarian follicles. Mol Reprod Dev, 40:391-399.

Sobinoff AP, Nixon B, Roman SD, McLaughlim EA. 2012. Staying Alive: PI3K Pathway Promotes Primordial Follicle Activation and Survival in Response to 3MC-Induced Ovotoxicity. Toxicol Sci 128, 258-271. Telfer EE, Zelinski MB. 2013. Ovarian follicle culture: advances and challenges for human and nonhuman primates. Fertil Steril, 99:1523-1533.

Wandji SA, Eppig JJ, Fortune JE. 1996a. FSH and 
growth factors affect the growth and endocrine function in vitro of granulosa cells of bovine preantral follicles. Theriogenology, 45:817-832.

Wandji SA, Srsen V, Voss AK, Eppig JJ, Fortune JE. 1996b. Initiation in vitro of growth of bovine primordial follicles. Biol Reprod, 55:942-948.

Zhang H, Risal S, Gorre N, Busayavalasa K, Li X, Shen Y, Bosbach B, Branstrom M, Liu K. 2014. Somatic Cells Initiate Primordial Follicle Activation and Govern the Development of Dormant Oocytes in Mice. Current Biology, 24:2501-2508.

Zhao Q, Ma Y, Sun NX, Ye C, Zhang Q, Sun SH, Xu C, Wang F, Li W. 2014. Exposure to bisphenol A at physiological concentrations observed in Chinese children promotes primordial follicle growth through the PI3K/Akt pathway in an ovarian culture system. Toxicol in Vitro, 28:1424-1429.

Zhao X, Dai W, Zhu H, Zhang Y, Cao L, Ye Q, Lei P, Shen G. 2006. Epidermal growth factor (EGF) induces apoptosis in a transfected cell line expressing EGF receptor on its membrane. Cell Biol Int, 30:653658.

Zhao Y, Zhang Y, Li J, Zheng N, Xu X, Yang J, Xialand G, Zhang M. 2017. MAPK3/1 participates in the activation of primordial follicles through mTORC1KITL signaling. $J$ Cell Physiol, 233(1):226-237. 